\title{
Assessment of renal glomerulosclerosis and thickness of the carotid intima-media complex as a means of age estimation in Western European bodies
}

\author{
Carl Daniel Lehmann-Leo ${ }^{1,2} \cdot$ Frank Ramsthaler $^{3} \cdot$ Christoph G. Birngruber $^{1} \cdot$ Marcel A. Verhoff $^{1}$
}

Received: 8 June 2021 / Accepted: 15 September 2021 / Published online: 13 November 2021

(c) The Author(s) 2021, corrected publication 2022

\begin{abstract}
Introduction The estimation of age-at-death of unidentified cadavers is a central aspect of the identification process. With increasing age, the incidence of glomerulosclerosis and the thickness of the carotid wall have been observed to also increase. This correlation has been demonstrated in various international histological studies. The aim of our study was to assess whether these correlations also apply to a Western European population.

Methodology In this retrospective observational study, kidney and common carotid artery samples from 216 cases autopsied at the Institute of Legal Medicine at the Justus-Liebig University in Giessen, Germany, were examined. Only cases with available tissue samples from both body sides were included. Exclusion criteria were poor sample quality and an age younger than 21 years. After histological processing, the tissue samples were assessed and digitally evaluated. Regression and classification analyses were used to investigate the correlation between age-at-death and intima-media thickness and age-at-death and the incidence of renal glomerular sclerosis.

Results Of the 216 autopsy cases, 183 were included for evaluation. Analysis of the carotid artery segments showed a strong correlation (Pearson correlation coefficient $r=0.887$ ) between the intima-media-complex thickness and chronological age. Classification of the glomerulosclerotic incidence showed a correlation of $37.7-43.1 \%$ with the predicted age group.

Discussion Both the intima-media thickness and the proportion of sclerotic glomeruli can be used to estimate age in Western European cadavers. On the basis of these results, both methods are suited to supplement other already established methods for age-at-death estimation in the identification of an unknown cadaver.
\end{abstract}

Keywords Forensic pathology $\cdot$ Age estimation $\cdot$ Biological profile $\cdot$ Sclerotic glomeruli $\cdot$ Glomerulosclerosis $\cdot$ Intimalmedial thickness

\section{Introduction}

As part of the forensic procedure to identify unknown decedents or victims of mass disasters, a "biological profile" is compiled. Age-at-death is one of the key characteristics

Marcel A. Verhoff

verhoff@med.uni-frankfurt.de

1 Institute of Legal Medicine, University Hospital of Frankfurt, Goethe University, Kennedyallee 104, 60596 Frankfurt/Main, Germany

2 Department of Anesthesiology, Operative Intensive Care Medicine and Pain Therapy, University Hospital Gießen and Marburg, Gießen, Germany

3 Institute of Legal Medicine, University of Saarland, HomburgSaar, Germany of this biological profile, which also includes data on sex, ancestry, stature, and the documentation of existing diseases [1]. With these postmortem data, potential matches can then be identified from missing persons lists.

During adolescence, up to an age of 21 years, age estimations are mainly of interest in legal contexts pertaining to criminal and asylum law [2]. Up to this age, methods that are useful for the estimation of age, in addition to anamnesis, are x-rays of the left hand (useful until about the 18th year of life) [3], panoramic dental radiographs to assess tooth mineralization status [4], and, in cases with completed skeletal growth of the hand-wrist, additional radiographic assessment of the medial epiphyseal clavicle by computed tomography [5-7]. These methods, based on changes of the growing skeleton, allow estimation of age with the requisite degree of medicolegal certainty needed to answer whether 
or not a legally relevant chronological age has been attained. Additionally, these methods can be helpful in estimating age-at-death in the identification of an unknown cadaver. Beyond the end of puberty, with complete ossification of the skeleton, which occurs approximately around the 21 st to the 23rd year of life, and the end of growth-dependent changes of the body, these methods are no longer of use. From this point on, in contrast to age estimation in juveniles, age-estimation methods based on degenerative changes and time-dependent effects on the body increasingly gain prominence for adults [8]. Moreover, the emphasis of age estimation in adults shifts from the determination of attained legally relevant age thresholds towards the identification of unknown decedents. Once skeletal growth has ceased, other methods for age estimation are therefore employed, such as assessment of a combination of several morphometric bone characteristics $[9,10]$, e.g., pubic symphysis $[11,12]$ and sternal rib ends [13], or methods based on various radiological and macroscopic dental characteristics [14-16].

More accurate age estimates in adults than those provided by classic anthropological methods can be achieved by measuring the racemization of aspartic acid in dentin [17, 18] or by determining incremental lines of dental cementum [19-21]. In addition, methods that allow age estimation on the basis of histological changes in bone structure have been published. Another more recent method from the field of epigenetics looks at age assessment on the basis of DNAmethylation markers [22-27].

Because these different methods have different estimation errors (histological bone features $\pm 5-10$ years (SE, standard error) $[9,10]$, aspartic acid racemization in dentin \pm 3 years (error) [18], telomere shortening \pm 9.8 years (SEE, standard error of estimate) [28], DNA-methylation \pm 3.75 years (MAD, mean absolute deviation) [26]), the accuracy of the estimated age interval can be increased by combining methods, especially by revealing discrepancies $[8,29,30]$. Moreover, it has been shown that the use of different methods, or combinations of methods, for individual age intervals delivers the best results [8, 31]. All of these methods, unfortunately, have limitations that can preclude their use on cadavers. If, as is sometimes the case in medicolegal case work, only highly decayed cadavers, isolated body parts, or tissue structures are available, it is of immense significance to be able to resort to a broad spectrum of established ageestimation methods. In this context, the quantification of age-related physiological changes in histological organ samples, such as the incidence of sclerotic glomeruli in kidneys, or increasing thickness of the intima media of the common carotid artery, appears to offer further options.

In the kidney, specific age-related changes in the glomeruli become apparent in the course of aging and can be histologically evaluated [32-35]. Due to age- and disease-related processes, there is increasing nephron rarefaction and, consecutively, loss of nephron structures. Hyaline deposits in the glomeruli become apparent and can be quantified. Because the proportion of glomeruli with hyaline deposits (sclerotic glomeruli) is known to increase with age, they are, thus, of interest as a means of forensic age estimation [36-41]. Several international studies have already demonstrated this correlation between the incidence of glomerular sclerosis and biological age [36-38, 42]. However, only one of these studies was conducted on a European population [37]. Since population-specific differences in the incidence of glomerulosclerosis are conceivable, the available data, therefore, currently precludes application of this method to a German population [36-38, 42]. Among other possible factors, in their study, Fukuda et al. discuss the effect of different lifestyles and eating habits as possible causes for such population-specific differences [42].

The results of epidemiological studies investigating atherosclerosis in cranial blood vessels showed that there was a sex-independent, age-related increase in the thickness of the carotid artery wall of $0.01 \mathrm{~mm} /$ year in vessel segments that were not affected by atherosclerosis [43]. In these studies, the intima-media thickness (IMT) of the common carotid artery could be determined in histological specimens as well as by sonography [43-45]. Determination of the intimamedia thickness of the common carotid artery could thus also be of interest in forensic age estimations.

The purpose of our study was to analyze a selected collective of autopsy cases from Germany, in regard to age-related glomerulosclerosis and intima-media thickness, with the aim of assessing the usefulness of these two parameters, as a means of estimating age in a Western European population.

\section{Material and methods}

This was an observational, retrospective study conducted on cadaveric histological kidney and common carotid artery samples from 216 decedents autopsied at the Institute of Legal Medicine at the Justus-Liebig University in Giessen, Germany, from 2010 through 2011. The ethics committee of the Goethe University in Frankfurt am Main, which was consulted whether approval for the study was necessary, ruled that none was required. There was no case selection on the basis of the decedents' age, sex, manner of death, or clinical history. The inclusion criterion for the case selection was that tissue samples from both kidneys and both common carotid arteries of the decedents were available. Tissue samples that could not be evaluated due to autolysis, putrefaction, and exhumation were excluded. Samples from decedents younger than 21 years of age were also excluded, based on the fact that the incidence of sclerosis in this age group is expected to be too low for analysis (Fig. 1). 
Fig. 1 Case selection. All cases with decedents aged between 21 and 89 years for whom histological kidney and carotid samples from both body sides were available for evaluation were included

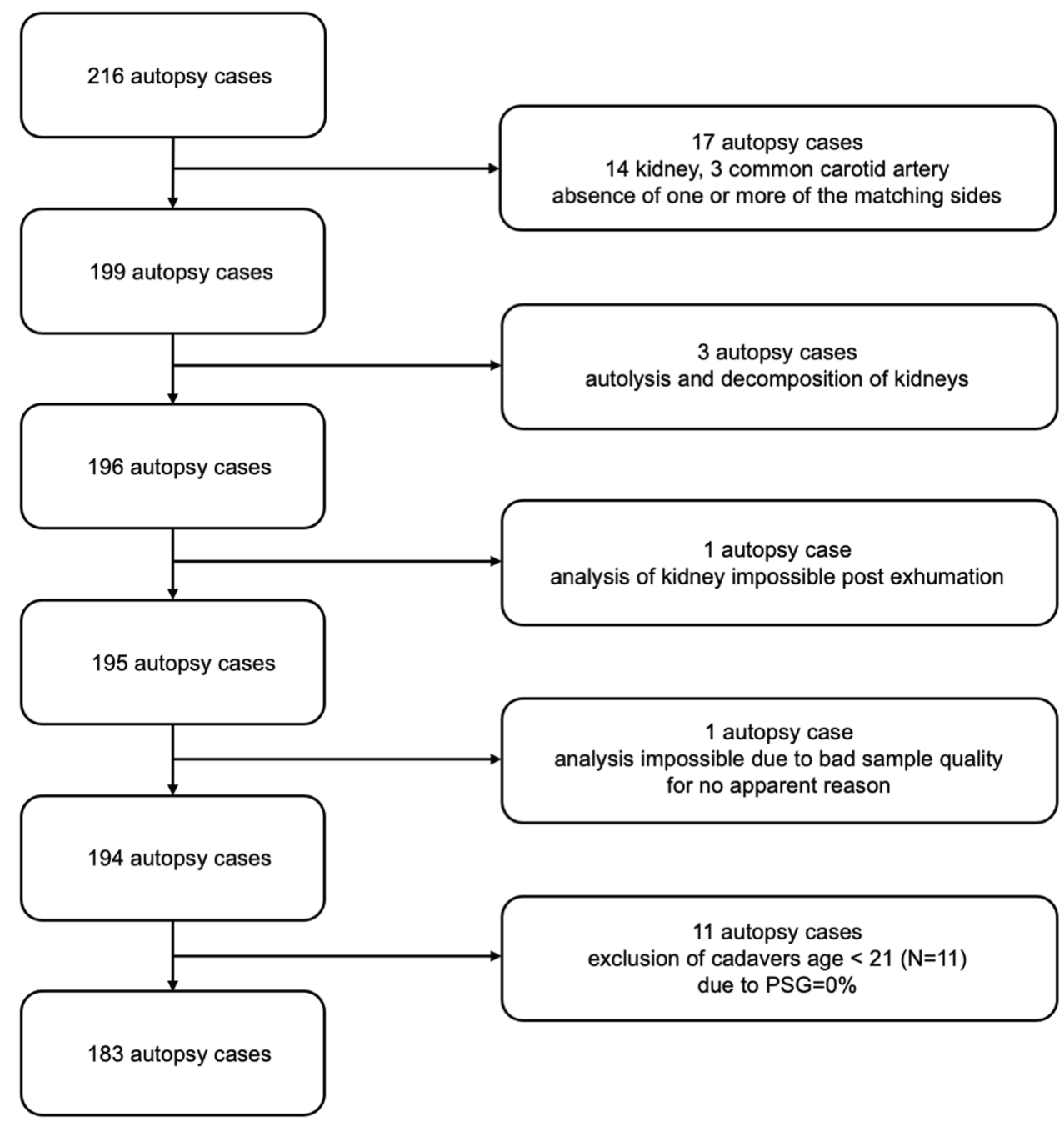

\section{Sample preparation}

Cadaveric tissue samples from both kidneys and both the left and right common carotid arteries were collected during forensic dissection. The tissue samples were fixed in $4 \%$ neutral buffered formaldehyde before being embedded in paraffin. The embedded samples were then sectioned and slices of 5-8 $\mu \mathrm{m}$ thickness were mounted on glass slides. Next, the paraffin was removed by passing the samples through decreasing concentrations of alcohol. The samples were then standardly stained with a hematoxylin-eosin stain, before being imaged with a light microscope $(40 \times$ magnification, light microscope BX51(TF), Olympus, Tokyo, Japan) and being digitized with a digital camera (camera DP72, Olympus, Tokyo, Japan).

\section{Quantification of sclerotic glomeruli}

To determine the proportion of sclerotic glomeruli, a tissue sample, measuring approx. $2.5 \mathrm{~cm} \times 1.5 \mathrm{~cm}$, was cut from a macroscopically inconspicuous horizontal section from the middle third of the renal cortex. This procedure was done for both kidneys. Per left and right kidney, ten non-overlapping, adjacent sections from the histologically prepared samples, measuring $2.23 \mathrm{~mm} \times 1.66 \mathrm{~mm}$, were photographed. Next, the total number of glomeruli and the number of hyalinized (sclerotic) glomeruli were counted in the images. Glomeruli on the edge of an image were included if at least $50 \%$ of the glomerulus was still clearly visible. A sclerotic glomerulus was defined as one that was completely sclerotized or completely filled with hyalinized material. Glomeruli that were only slightly or moderately hyalinized were not counted as sclerotic for better comparison with existing studies on the topic [42]. Figure 2, for comparison, shows images of normal samples, hyalinized samples, and samples that could not be evaluated.

The samples were counted in a blinded evaluation, i.e., the examiner did not know the decedent's age, sex, medical history, or manner of death. The numbers of sclerotic and non-sclerotic glomeruli were subsequently added together, and the quotient was determined (sclerotic/nonsclerotic glomeruli). 
A

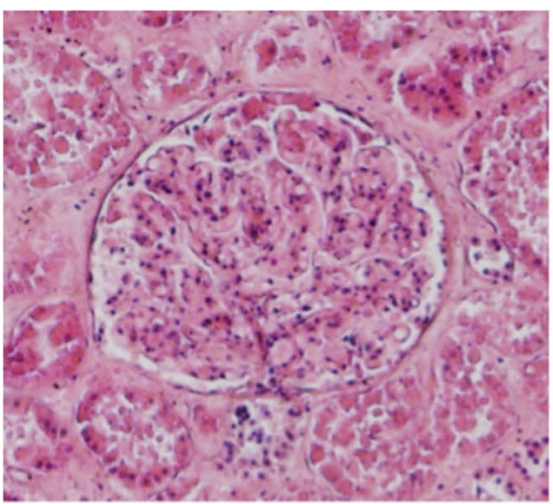

B

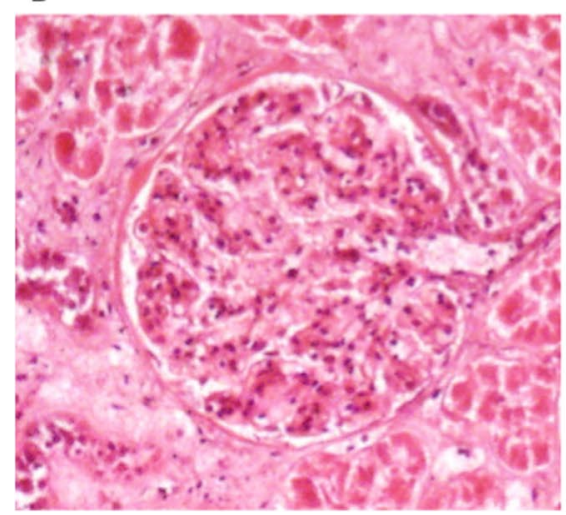

C

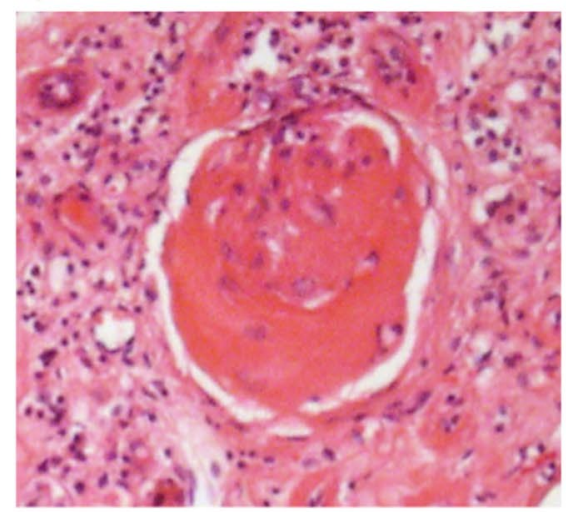

D

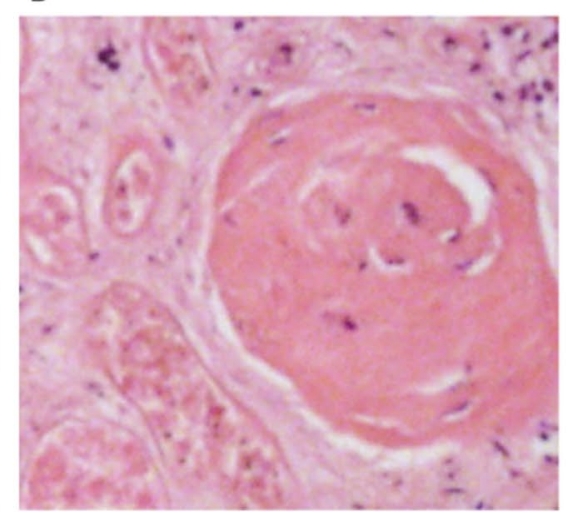

$\mathrm{E}$

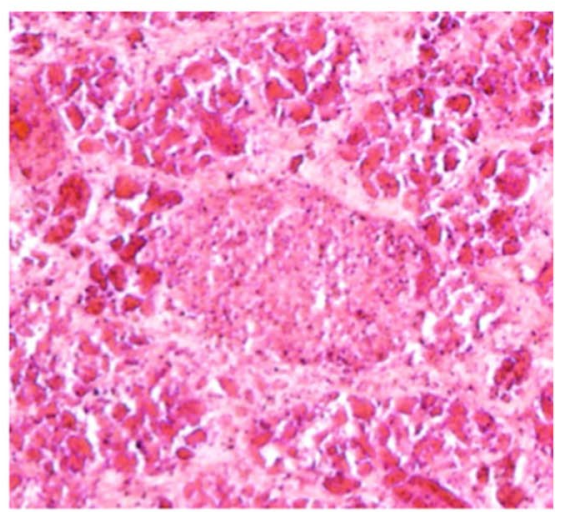

$\mathrm{F}$

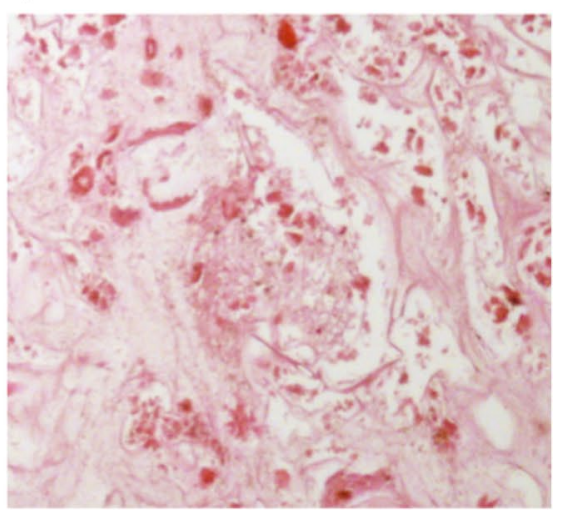

Fig. 2 Non-sclerotic renal glomerulus $(\mathbf{A}+\mathbf{B})$; sclerotic glomerulus $(\mathbf{C}+\mathbf{D})$; renal glomerulus after putrefaction and autolysis $(\mathbf{E})$; kidney after exhumation, PMI 492 days (F)

\section{Quantification of the intimal-medial thickness in carotid artery segments}

To determine the IMT of the carotid arteries, a 1-cm-long vessel segment was removed immediately proximal to the carotid bifurcation, both for the left and the right carotid artery (online supplementary material). After fixation of the arterial segments, between 1 and 11 digital images were captured per side (size $2.23 \mathrm{~mm} \times 1.66 \mathrm{~mm}$ ).

Each of the digital images was then subdivided into 3 equal sections, and the IMT in each section was manually measured (Fig. 3) (Fiji ImageJ Version 2.0.0-rc-69/1.52i, GitHub, San Francisco, USA). The IMT was defined as the distance between the vessel lumen (border of vessel lumen and tunica intima) and the edge of the tunica media (border of tunica media and tunica externa/tunica adventitia). The mean value for the measurements from the subsections was calculated for further evaluation.

\section{Statistical analysis}

Statistical analysis was performed with MedCalc Software Ltd Belgien, MedCalc Version 19.0.3 (7. Mai 2019). The descriptive analysis encompassed the mean value, standard deviation, and variance.

For the statistical analysis of the hyalinized glomeruli, the histologically prepared samples were sorted by sex and body side and then grouped into 4 classes of sclerosis incidence (Class 0: No sclerosis; Class 1:>0 to 5\%; Class $2:>5$ to $10 \%$; Class 3:>10\% sclerosis). These classes were then assigned to age groups of 21-35 years, 36-50 years, 51-65 years, and $>65$ years. Subsequently, this assignment to a (predicted) age group on the basis of the above criteria was controlled by comparison with the true age-at-death of the decedent from whom the histological sample had been taken. Four sub-classes, divided by sex (male/female) and body side (left/right), were looked at.

To statistically analyze the correlation between age and IMT, the Pearson correlation coefficient and the standard error of estimation (SEE) were calculated. Furthermore, three regression models (linear, potential, and exponential regression) were investigated to describe the correlation, and the highest coefficient of determination $\left(R^{2}\right)$ was identified. The purpose of this statistical procedure was to identify the lowest variance in a regression model used to describe the statistical correlation between IMT and biological age. 
a

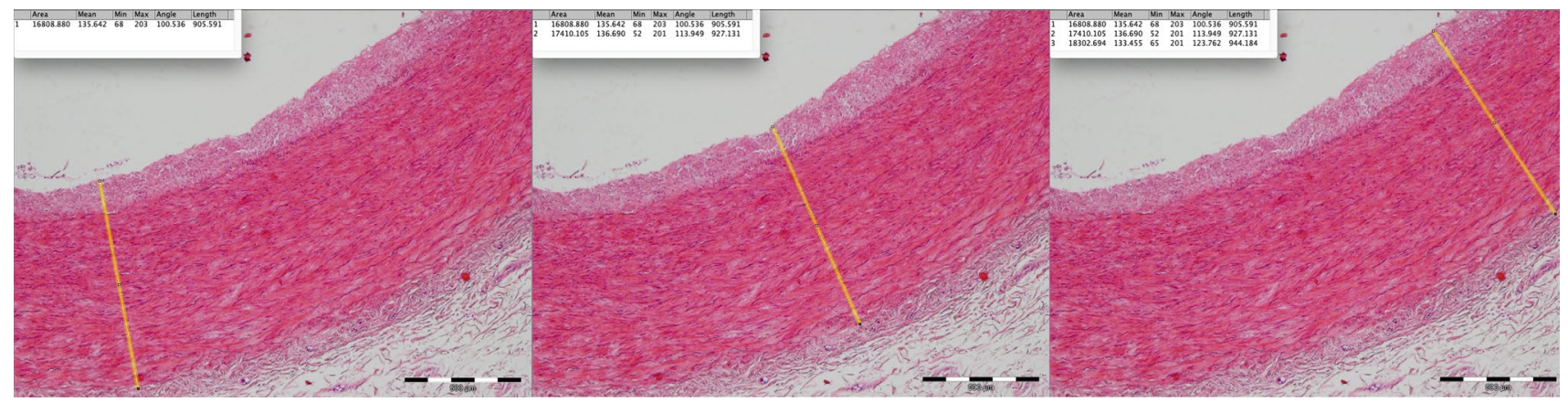

b

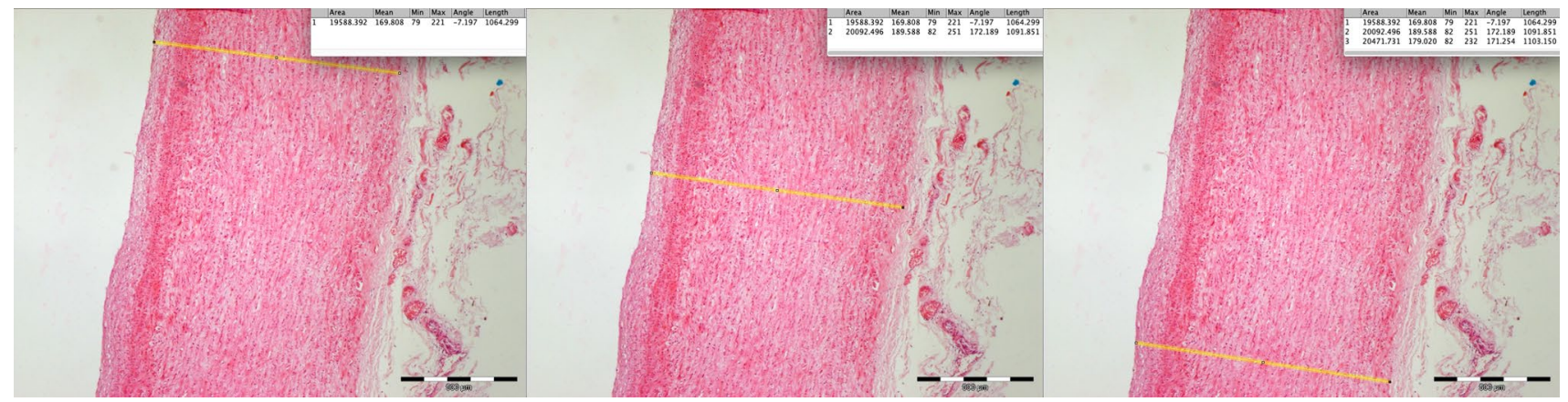

C

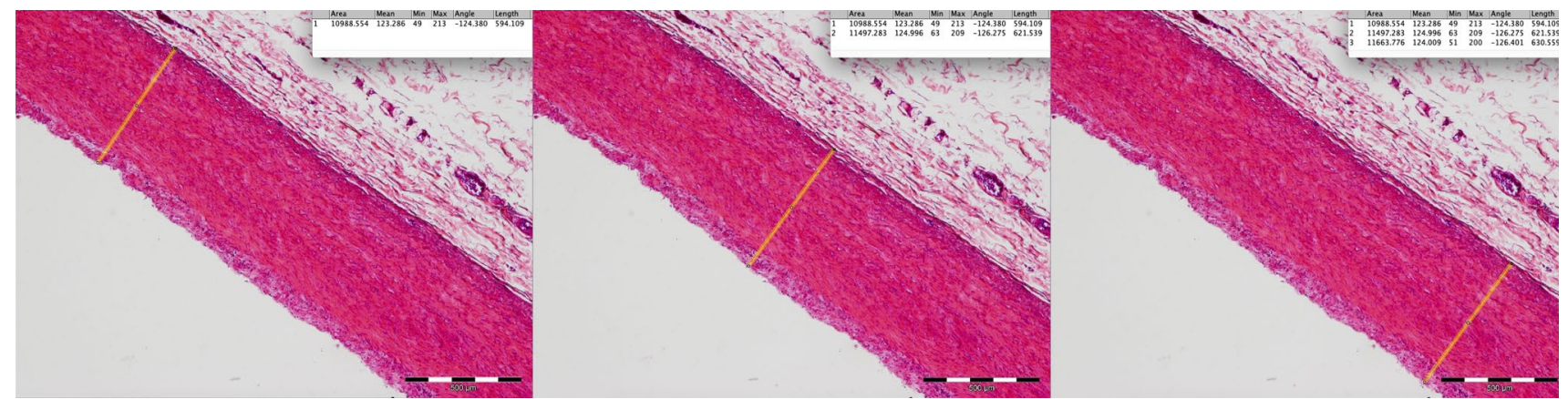

Fig. 3 a-c Measurement of the IMT of the common carotid artery Three measurements per sample were taken and the mean value was then calculated

For age estimation in the examined cases, canonical classification (discriminant function) analysis was used together with the evaluated characteristics for predicting the age group an individual belonged to.

\section{Results}

\section{Basic characteristics}

After application of the inclusion and exclusion criteria, cadaveric samples from 183 of 216 autopsied cases were analyzed (Table 1). In one case, the reason for the poor quality of the prepared kidney sample could not be elucidated from the documentation. The exclusion of autopsy cases due to poor quality of the processed histological samples was, in all cases, related only to kidney tissues. This exclusion criterion had no bearing on the assessment of the IMT of the carotid arteries, and the carotid tissue preparations could be evaluated for all of the 216 decedents. However, in some of the cases, carotid samples were only available from one side of the body. Retrospective assessment of our histological samples after reviewing the dissection records in regard to kidney-altering diseases and arterial hypertension did not allow the conclusion that these diseases might have affected the results of our evaluations. 
Table 1 Demographics and characteristics of the included forensic autopsy cases

\begin{tabular}{lll}
\hline Number of cases & Total & 183 \\
& For both sides & 366 \\
\hline Cases per age group (years) & $21-35$ & 36 \\
& $36-50$ & 42 \\
& $51-65$ & 47 \\
& $>65$ & 58 \\
Sex & Male & $130(71 \%)$ \\
\multirow{2}{*}{ Postmortem interval (days) } & Female & $53(29 \%)$ \\
& Minimum & 0 \\
& Maximum & 31 \\
\hline
\end{tabular}

The recorded postmortem interval (PMI, time since death in days) had been less than 5 days in $71.6 \%$ of the autopsy cases and above 10 days in seven of the cases $(3.8 \%)$.

Table 2 depicts the descriptive statistical evaluation for the sclerotic glomeruli and the carotid IMT, without additional preselection or filters.

\section{Correlation of sclerotic glomeruli and biological age}

The histological samples from the left kidney of female cadavers were correctly classified in $37.7 \%$ of the cases $[n=20 / 53]$; in the case of the male cadavers, the samples for the left kidney were correctly classified in $43.1 \%$ of the cases $[n=56 / 130]$. For histological samples from the right kidney, the classification was correct for $37.7 \%$ of the female cadavers [ $n=20 / 53$ ], and correct in $40.8 \%$ of the cases [ $n=53 / 130]$ for the male cadavers.

The classification by body side (left/right) and sex is presented in the online supplementary material.

\section{Correlation of the intimal-medial thickness of the carotid artery and biological age}

No significant difference in the IMT of the common carotid arteries could be found between the left and the right carotid. Similarly, no significant difference in IMT could be found between men and women (Fig. 4).

At a level of $p=0.01$ (one sided) and $r=0.887$, the Pearson correlation coefficient showed highly significant correlation between biological age of the individual and IMT.

Without application of selection criteria (i.e., all PMI, all age groups, left and right body sides together), there was a high standard estimation error (SEE: 13.9-14.0) in the regression analysis.

Better results could be achieved when the postmortem interval was restricted to less than 5 days, and the left and right body sides, and both sexes were looked at separately. For each sub-group (in total 6), three regression models (L: Linear, P: Potential, E: Exponential) were looked at and compared. Table 3 shows the results of the regressions for the various models and sub-groups. Figure 5 shows the subgroup composed of the right carotid artery and PMI of less than 5 days. The results for the six sub-groups that were analyzed did not vary significantly from each other.

\section{Discussion}

The aim of this study was to investigate the correlation between renal glomerulosclerosis and age-at-death, as well as between common carotid artery intima-media thickness (IMT) and age-at-death, for a cadaver population from Germany. Forensic age estimations, which are performed in the context of compiling a "biological profile," investigate biological age [46]. The ultimate aim of these age estimations is to be able to narrow down, or estimate, a decedent's chronological age. Biological age itself only describes the

Table 2 Descriptive statistics for sclerotic glomeruli and the IMT, without filters

\begin{tabular}{|c|c|c|c|c|c|c|}
\hline & Number $(N)$ & Minimum & Maximum & Mean value & Standard deviation & Variance \\
\hline Age & 366 & 21 & 89 & 54.45 & 18.308 & 335.185 \\
\hline Number glomeruli & 366 & 56 & 204 & 118.01 & 22.273 & 496.101 \\
\hline Percent glomeruli & 366 & 0.0 & 96.1 & 3.73 & 6.565 & 43.096 \\
\hline $\begin{array}{l}\text { Number of measure- } \\
\text { ments IMT }\end{array}$ & 366 & 3 & 33 & 16.58 & 5.154 & 26.562 \\
\hline IMT minimum & 366 & 260 & 1090 & 714.94 & 144.722 & $20,944.435$ \\
\hline IMT maximum & 366 & 539 & 1631 & 996.68 & 189.142 & $35,774.760$ \\
\hline IMT mean values & 366 & 468 & 1241 & 843.51 & 148.585 & $22,077.440$ \\
\hline
\end{tabular}

The table presents the descriptive statistics for sclerotic glomeruli and IMT of the carotid artery after application of inclusion and exclusion criteria 
Fig. 4 Distribution of IMD mean value according to sex

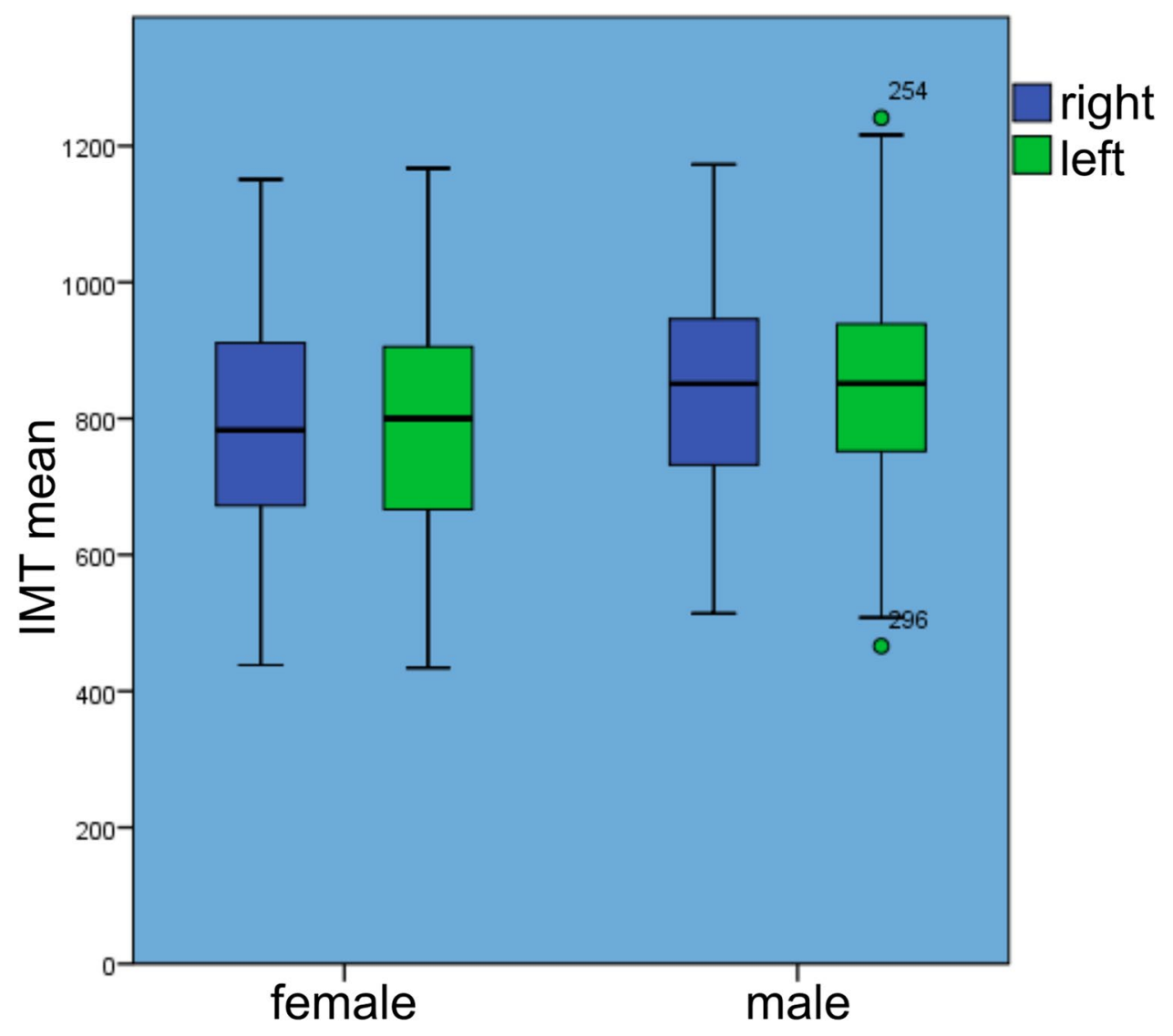

Table 3 Regression analyses for the IMT of the common carotid artery

\begin{tabular}{|c|c|c|c|c|c|c|c|}
\hline Selection & Number $(N)$ & & Regression formula & $R$ & $R^{2}$ & $p$ & SEE \\
\hline \multirow{3}{*}{$\begin{array}{l}\text { Right side, } \\
\mathrm{PMI}<5 \text { days }\end{array}$} & \multirow[t]{3}{*}{131} & $\operatorname{lin}$ & $y=0.110 x+(-39.725)$ & 0.844 & 0.71 & $<0.001$ & 8.07 \\
\hline & & pot & $y=0.0001 * \times 1.885$ & 0.86 & 0.739 & $<0.001$ & 8.12 \\
\hline & & $\exp$ & $y=7.529 * \exp (0.0022 * x)$ & 0.848 & 0.719 & $<0.001$ & 8.55 \\
\hline \multirow{3}{*}{$\begin{array}{l}\text { Right side, male } \\
\mathrm{PMI}<5 \text { days }\end{array}$} & \multirow[t]{3}{*}{99} & $\operatorname{lin}$ & $y=0.106 x+(-37.45)$ & 0.83 & 0.69 & $<0.001$ & 8.26 \\
\hline & & pot & $y=0.0001 * \times 1.868$ & 0.85 & 0.73 & $<0.001$ & 8.36 \\
\hline & & $\exp$ & $y=7.413 * \exp (0.0022 * x)$ & 0.84 & 0.71 & $<0.001$ & 8.9 \\
\hline \multirow{3}{*}{$\begin{array}{l}\text { Right side, female, } \\
\text { PMI }<5 \text { days }\end{array}$} & \multirow[t]{3}{*}{32} & $\operatorname{lin}$ & $y=0.122 x+(-46.95)$ & 0.887 & 0.78 & $<0.001$ & 6.3 \\
\hline & & pot & $y=0.0001 * \times 1.932$ & 0.886 & 0.78 & $<0.001$ & 6.35 \\
\hline & & $\exp$ & $y=7,74 * \exp (0.0022 * x)$ & 0.877 & 0.71 & $<0.001$ & 6.74 \\
\hline \multirow{3}{*}{$\begin{array}{l}\text { Left side, } \\
\mathrm{PMI}<5 \text { days }\end{array}$} & \multirow[t]{3}{*}{131} & $\operatorname{lin}$ & $y=0.102 x+(-32.20)$ & 0.80 & 0.64 & $<0.001$ & 8.5 \\
\hline & & pot & $y=0.0039 * \times 1.749$ & 0.81 & 0.66 & $<0.001$ & 8.7 \\
\hline & & $\exp$ & $y=8.75^{*} \exp (0.0020 * x)$ & 0.80 & 0.64 & $<0.001$ & 9.1 \\
\hline \multirow{3}{*}{$\begin{array}{l}\text { Left side, male, } \\
\mathrm{PMI}<5 \text { days }\end{array}$} & \multirow[t]{3}{*}{99} & $\operatorname{lin}$ & $y=0.104 x+(-35.32)$ & 0.825 & 0.677 & $<0.001$ & 8.09 \\
\hline & & pot & $y=0.0002 * \times 1.835$ & 0.84 & 0.71 & $<0.001$ & 8.31 \\
\hline & & $\exp$ & $y=7.14 * \exp (0.0021 * x)$ & 0.83 & 0.68 & $<0.001$ & 8.3 \\
\hline \multirow{3}{*}{$\begin{array}{l}\text { Left side, female, } \\
\mathrm{PMI}<5 \text { days }\end{array}$} & \multirow[t]{3}{*}{32} & $\operatorname{lin}$ & $y=0.099 x+(-25.69)$ & 0.78 & 0.59 & $<0.001$ & 8.24 \\
\hline & & pot & $y=0.0012 * \times 1.530$ & 0.76 & 0.56 & $<0.001$ & 8.4 \\
\hline & & $\exp$ & $y=11.39 * \exp \left(0.0018^{*} x\right)$ & 0.75 & 0.56 & $<0.001$ & 8.75 \\
\hline
\end{tabular}

The table depicts the different regression models and selections. Abbreviations: $R$, correlation coefficient; $R^{2}$, coefficient of determination; $p$, significance value; $S E E$, standard error of estimation 
Fig. 5 Regressions curves for the mean values for IMT and age for the right carotid artery and a PMI of less than 5 days

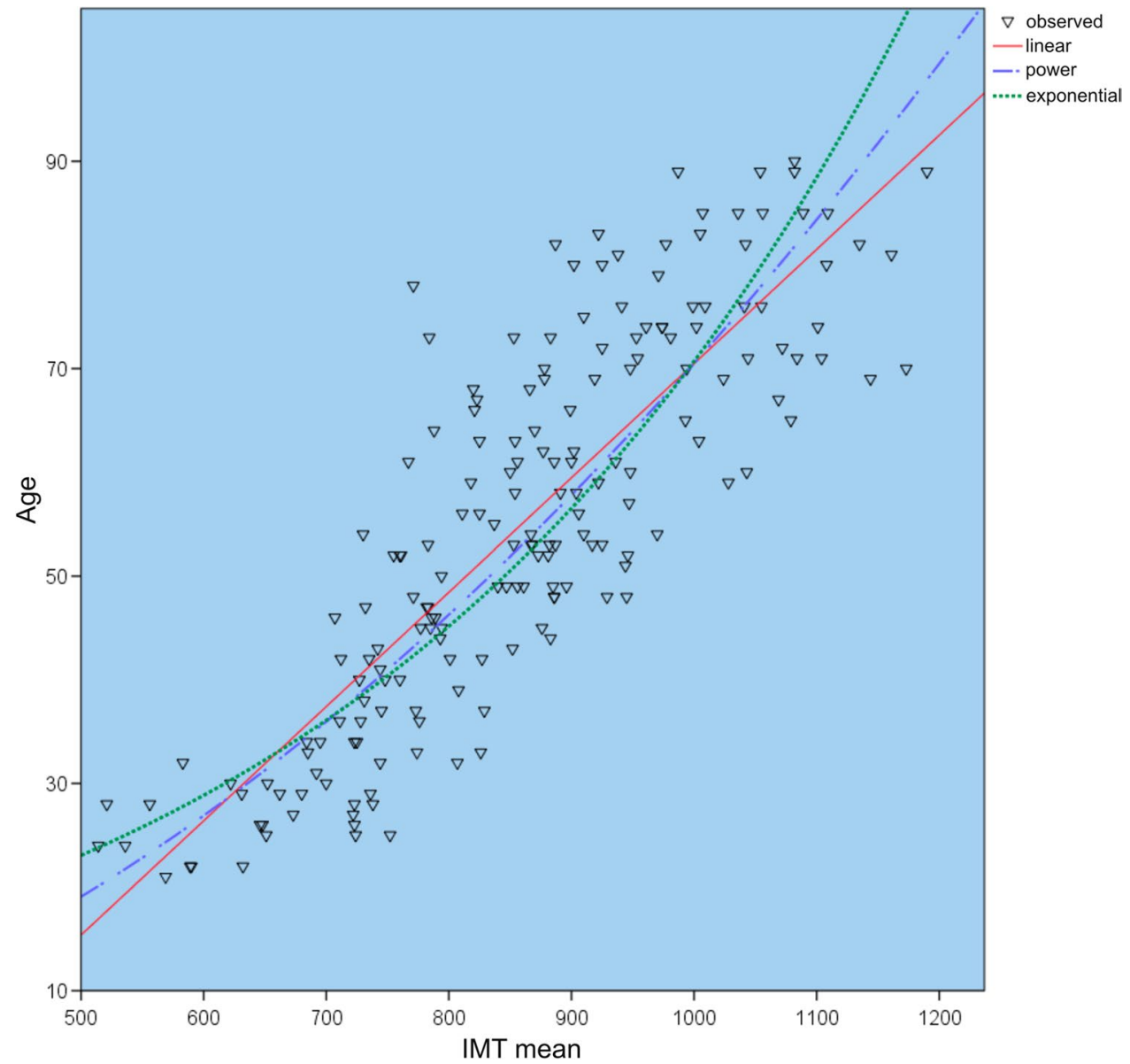

physiological condition of an individual, which is influenced not only by genetics and environmental factors, but in the course of a life, increasingly also by lifestyle, e.g., diet, use of stimulants/alcohol, or exercise [47]. As these factors increasingly affect biological age with increasing chronological age, the discrepancy between biological and chronological age may widen, an effect that has been termed the "trajectory effect" by Nawrocki [48]. The aim in estimating the age of an unidentified cadaver is thus to use various methods to achieve the best possible agreement between biological and chronological age.

The hyalinization of renal glomeruli over the course of a lifetime is an example of such a natural, physiological process, as the incidence of sclerotic glomeruli increases with increasing age, throughout life [36-42]. While for age groups younger than 21 years old, no sclerotic glomeruli (PSG $=0 \%$ ) are observed, and up to the age of 30 years, on average, only $1 \%$ of glomeruli are obsolescent. Thereafter, the hyalinization slowly increases but rarely exceeds $7 \%$ below the age of 50 years. Between the age of 50 and 66 years, PSG is usually less than $12 \%$, whereas after the age of 66 years, the rate of sclerosis varies greatly. This seems a little different to the results of Fukuda et al. [42] in which the rate of sclerosis in the Japanese population was less than $0.6 \%$ in age groups younger than 33 years old, and a sclerosis rate of $6 \%$ with high probability indicated an age of older than 55 years. For the USA, Kaplan et al.[36] demonstrated that up to age 40 to 45 years it would be expected to have PSG values no greater than 10\%; however, after the age 45 to 50 years, the observed values exceeded $10 \%$ with a broad scatter. Based on the observed differences in the individual collectives, population-specific differences appear possible due to the reasons listed above.

In our study, in which we subdivided the age span of the autopsied decedents, which had ranged from 21 to 89 years, into four groups, or age intervals, the kidney samples could be assigned to their predicted age group with an accuracy of $37.7-43.1 \%$. Because of the high variability in estimation errors for the currently established methods, the ability by itself to narrow down a decedent's age to a certain age group and in combination with different methods can be decisive for the positive identification of an unknown body.

The IMT of the common carotid artery is used as a biomarker for the early detection of systemic atherosclerosis. Apart from cardiovascular risk factors, chronological age is an important independent factor affecting IMT [45]. The 
positive correlation between age and IMT has previously been demonstrated in several epidemiological studies [43, 45, 49], and increasing IMT may represent a normal aging process of vessels [45]. Sonographic and histological measurements of the IMT have been shown to be comparable and to not differ significantly $[44,50]$. These findings suggest that determination of the IMT of the carotid artery could be a means to estimate the age-at-death of an unknown cadaver. In the autopsied cadaver collective we investigated, we could also demonstrate a strong correlation between an increase in IMT of the common carotid artery and age by using different regression analyses (Pearson correlation coefficient $r=0.887$ ). Despite the fact that no significant group differences were found in the IMT analysis, selection of the samples proved useful (male/female, left/right), as this increased the estimation accuracy. Although there was no statistically significant difference between the selected groups, the standard deviation of the estimation error (SEE. 6.3-9.1) could be reduced and, consequently, a better fit of the regression curves could be achieved.

In contrast to the kidney samples, histological evaluation of the carotid artery samples was possible in each of the examined autopsy cases. In the case of the five kidney samples that could not be evaluated, the poor sample quality had been mainly due to extreme external factors (warm surroundings) that had led to autolysis and putrefaction, or a very long PMI (exhumation). This suggests that the tissue from the carotid arteries was more robust towards autolysis and putrefaction than the kidney tissue. Although most of the 183 forensic autopsies included in our study had a PMI of less than 5 days (71.6\%), evaluation of all tissue samples was still possible even for PMIs of longer than 10 days, provided they had not been exposed to extreme external factors. The carotid artery samples could be evaluated in every case, in as far as they were available.

The strength of the age-estimation methods we investigated here lies in the simplicity of their application, since even for incomplete cadavers, or those in a compromised condition, it is usually possible to at least obtain tissue samples from both sides of the body and to determine the sex of the decedent. As a limitation in our study, it must be noted that our methods were not tested on badly decomposed cadavers. However, it is generally agreed on that connective tissues and structures embedded in those tend to stay stable for a longer time during the process of decomposition. Therefore, we assume that they will be available for examination for a longer time frame; nevertheless, further systematic postmortem studies are required to prove this. To improve the accuracy of age estimations, the sex and ancestry of the decedent should be taken into consideration and, whenever possible, population-specific standards for age estimation should be used [51]. We could corroborate the importance of these aspects by achieving a reduction in the standard error of estimation through selection of our samples.
The information on past medical history obtained from medical examiner records and in general in the case of the identification of an unknown body is usually poorer than in hospital cases. We did not compare our limited available data with those of hospital cases. In their study, Kaplan et al. [36] demonstrated that medicolegal cases are parallel to hospital cases. Fukuda et al. [42] also stated that the correlation found in their study and in previous reports suggests that the effects of renal diseases and hypertension in medical examiner cases are negligible.

In our study, there was no case with a documented history of renal disease, diabetes, or hypertension. During our examination, only one specimen showed visible pathological changes which could be attributed to a disease.

In summary, two different methods for age-at-death estimations for Western European cadavers were investigated in this study: the IMT of the carotid artery and the incidence of glomerulosclerosis. The IMT of the carotid artery reliably demonstrated a strong correlation with biological age. A part of the histological kidney samples could also be assigned to the correct age range by classifying the incidence of sclerotic glomeruli to four age groups. Thus, both methods, on their own and in combination with each other, appear to be useful supplements to other established methods (e.g., osteological methods) for the estimation of age-at-death in the compilation of a "biological profile" for an unknown body.

Supplementary Information The online version contains supplementary material available at https://doi.org/10.1007/s00414-021-02705-w.

Funding Open Access funding enabled and organized by Projekt DEAL.

\section{Declarations}

Ethical approval The ethics committee of the Goethe-University in Frankfurt am Main, which was consulted whether approval for the study was necessary, ruled that none was required.

Informed consent Not applicable/required.

Research involving human participants, their data, or biological material The data were pseudonymized; the material was acquired during routine autopsies with no additional injury to the corpse.

Conflict of interest The authors declare no competing interests.

Open Access This article is licensed under a Creative Commons Attribution 4.0 International License, which permits use, sharing, adaptation, distribution and reproduction in any medium or format, as long as you give appropriate credit to the original author(s) and the source, provide a link to the Creative Commons licence, and indicate if changes were made. The images or other third party material in this article are included in the article's Creative Commons licence, unless indicated otherwise in a credit line to the material. If material is not included in the article's Creative Commons licence and your intended use is not permitted by statutory regulation or exceeds the permitted use, you will need to obtain permission directly from the copyright holder. To view a copy of this licence, visit http://creativecommons.org/licenses/by/4.0/. 


\section{References}

1. Adserias-Garriga J (ed) (2019) Age estimation: a multidisciplinary approach. Academic Press, London

2. Hagen M, Schmidt S, Schulz R et al (2020) Forensic age assessment of living adolescents and young adults at the Institute of Legal Medicine, Münster, from 2009 to 2018. Int J Legal Med 134:745-751. https://doi.org/10.1007/s00414-019-02239-2

3. Schmidt S, Nitz I, Ribbecke S et al (2013) Skeletal age determination of the hand: a comparison of methods. Int J Legal Med 127:691-698. https://doi.org/10.1007/s00414-013-0845-4

4. Demirjian A, Goldstein H, Tanner JM (1973) A new system of dental age assessment. Hum Biol 45:211-227

5. Schmeling A, Schmidt S, Schulz R et al (2014) Studienlage zum zeitlichen Verlauf der Schlüsselbeinossifikation. Rechtsmedizin 24:467-474. https://doi.org/10.1007/s00194-014-0989-7

6. Hermetet C, Saint-Martin P, Gambier A et al (2018) Forensic age estimation using computed tomography of the medial clavicular epiphysis: a systematic review. Int J Legal Med 132:1415-1425. https://doi.org/10.1007/s00414-018-1847-z

7. Rudolf E, Kramer J, Winkler I, Schmeling A (2019) Technical note: utilization of 3D-rendering for CT evaluation of extremitas sternalis claviculae within medical age assessment practice. Int J Legal Med 133:931-934. https://doi.org/10.1007/ s00414-019-02025-0

8. Adserias-Garriga J, Zapico SC (2018) Age assessment in forensic cases: anthropological, odontological and biochemical methods for age estimation in the dead. Mathews J Forensic Res 1:001. https://www.mathewsopenaccess.com/scholarly-articles/ age-assessment-in-forensic-cases-anthropological-odontologicaland-biochemical-methods-for-age-estimation-in-the-dead.pdf

9. Kerley ER (1965) The microscopic determination of age in human bone. Am J Phys Anthropol 23:149-163. https://doi.org/10.1002/ ajpa. 1330230215

10. Uytterschaut HT (1985) Determination of skeletal age by histological methods. Z Morphol Anthropol 75:331-340

11. Brooks ST (1955) Skeletal age at death: the reliability of cranial and pubic age indicators. Am J Phys Anthropol 13:567-597. https://doi.org/10.1002/ajpa.1330130403

12. Todd TW (1921) Age changes in the pubic bone. VI. The interpretation of variations in the symphysial area. Am J Phys Anthropol 4:407-424. https://doi.org/10.1002/ajpa.1330040403

13. İşcan MY, Loth SR, Wright RK (1984) Metamorphosis at the sternal rib end: a new method to estimate age at death in white males. Am J Phys Anthropol 65:147-156. https://doi.org/10.1002/ ajpa. 1330650206

14. Solheim T (1993) A new method for dental age estimation in adults. Forensic Sci Int 59:137-147. https://doi.org/10.1016/03790738(93)90152-Z

15. Soomer H, Ranta H, Lincoln M, Penttilä A (2003) Reliability and validity of eight dental age estimation methods for adults. J Forensic Sci 48:149-152. https://doi.org/10.1520/JFS2002253

16. Kvaal SI, Sellevold BJ, Solheim T (1994) A comparison of different non-destructive methods of age estimation in skeletal material. Int J Osteoarchaeol 4:363-370. https://doi.org/10.1002/oa.1390040410

17. Ritz-Timme S, Rochholz G, Schütz HW et al (2000) Quality assurance in age estimation based on aspartic acid racemisation. Int $\mathbf{J}$ Legal Med 114:83-86. https://doi.org/10.1007/s004140000159

18. Ohtani S (1995) Estimation of age from the teeth of unidentified corpses using the amino acid racemization method with reference to actual cases. Amercian J Forensic Med Pathol 16:238-242. https://doi.org/10.1097/00000433-199509000-00010

19. Jankauskas R, Barakauskas S, Bojarun R (2001) Incremental lines of dental cementum in biological age estimation. HOMO- J Comp Hum Biol 52:59-71. https://doi.org/10.1078/0018-442X-00020
20. Kagerer P, Grupe G (2001) On the validity of individual ageat-death diagnosis by incremental line counts in human dental cementum. Tech Consider Anthropol Anzeiger 59:331-342. https://doi.org/10.1127/anthranz/59/2002/331

21. Wittwer-Backofen U, Gampe J, Vaupel JW (2004) Tooth cementum annulation for age estimation: results from a large known-age validation study. Am J Phys Anthropol 123:119-129. https://doi. org/10.1002/ajpa.10303

22. Xin Y, Dong K, Cao F et al (2019) Studies of hTERT DNA methylation assays on the human age prediction. Int J Legal Med 133:1333-1339. https://doi.org/10.1007/s00414-019-02076-3

23. Freire-Aradas A, Phillips CP, Lareu MV (2017) Forensic individual age estimation with DNA: from initial approaches to methylation tests. Forensic Sci Rev 29:121-144

24. Shi L, Jiang F, Ouyang F et al (2018) DNA methylation markers in combination with skeletal and dental ages to improve age estimation in children. Forensic Sci Int Genet 33:1-9. https://doi. org/10.1016/j.fsigen.2017.11.005

25. Zubakov D, Liu F, Kokmeijer I et al (2016) Human age estimation from blood using mRNA, DNA methylation, DNA rearrangement, and telomere length. Forensic Sci Int Genet 24:33-43. https://doi. org/10.1016/j.fsigen.2016.05.014

26. Bekaert B, Kamalandua A, Zapico SC et al (2015) Improved age determination of blood and teeth samples using a selected set of DNA methylation markers. Epigenetics 10:922-930. https://doi. org/10.1080/15592294.2015.1080413

27. Márquez-Ruiz AB, González-Herrera L, de Luna JD, Valenzuela A (2020) DNA methylation levels and telomere length in human teeth: usefulness for age estimation. Int J Legal Med 134:451-459. https://doi.org/10.1007/s00414-019-02242-7

28. Ren F, Li C, Xi H et al (2009) Estimation of human age according to telomere shortening in peripheral blood leukocytes of Tibetan. Am J Forensic Med Pathol 30:252-255. https://doi.org/10.1097/ PAF.0b013e318187df8e

29. Schmeling A, Dettmeyer R, Rudolf E et al (2016) Forensic age estimation - methods, certainty, and the law. Dtsch Aerzteblatt Int 113:44-50. https://doi.org/10.3238/arztebl.2016.0044

30. Martrille L, Ubelaker DH, Cattaneo C et al (2007) Comparison of four skeletal methods for the estimation of age at death on white and black adults. J Forensic Sci 52:302-307. https://doi.org/10. 1111/j.1556-4029.2006.00367.x

31. Verhoff MA, Kreutz K, Jopp E, Kettner M (2013) Forensische Anthropologie im 21. Jahrhundert: Bestandsaufnahme. Rechtsmedizin 23:79-84. https://doi.org/10.1007/s00194-013-0873-x

32. Woodhouse MA, Darmady EM, Offer J (1973) The parameters of the ageing kidney. J Pathol 109:195-207. https://doi.org/10.1002/ path. 1711090304

33. Lonergan ET (1988) Aging and the kidney: adjusting treatment to physiologic change. Geriatrics 43:27-33

34. Anderson S, Brenner BM (1986) Effects of aging on the renal glomerulus. Am J Med 80:435-442. https://doi.org/10.1016/0002-9343(86)90718-7

35. McLachlan MSF, Guthrie JC, Anderson CK, Fulker MJ (1977) Vascular and glomerular changes in the ageing kidney. J Pathol 121:65-78. https://doi.org/10.1002/path.1711210202

36. Kaplan C, Pasternack B, Shah H, Gallo G (1975) Age-related incidence of sclerotic glomeruli in human kidneys. Am J Pathol 80:227-234

37. Kappel B, Olsen S (1980) Cortical interstitial tissue and sclerosed glomeruli in the normal human kidney, related to age and sex - a quantitative study. Virchows Arch A Pathol Anat Histol 387:271-277. https://doi.org/10.1007/BF00454830

38. Chan KW, Leung CY, Chan CW (1990) Age-related glomerular sclerosis: baseline values in Hong Kong. Pathology 22:177-180. https://doi.org/10.3109/00313029009086656

39. Meleg Smith S, Hoy WE, Cobb L (1989) Low incidence of glomerulosclerosis in normal kidney. Arch Pathol Lab Med 113:1253-1255 
40. Neugarten J, Gallo G, Silbiger S, Kasiske B (1999) Glomerulosclerosis in aging humans is not influenced by gender. Am J Kidney Dis 34:884-888. https://doi.org/10.1016/S0272-6386(99)70046-6

41. Kasiske BL (1987) Relationship between vascular disease and age-associated changes in the human kidney. Kidney Int 31:11531159. https://doi.org/10.1038/ki.1987.122

42. Fukuda N, Suzuki Y, Sato K et al (2010) Estimation of age from sclerotic glomeruli. Forensic Sci Int 197:123.e1-4. https://doi.org/ 10.1016/j.forsciint.2009.12.062

43. Howard G, Sharrett AR, Heiss G et al (1993) Carotid artery intimal-medial thickness distribution in general populations as evaluated by B-mode ultrasound. ARIC Investigators Stroke 24:1297-1304. https://doi.org/10.1161/01.STR.24.9.1297

44. Manninen HI, Rasanen H, Vanninen RL et al (1998) Human carotid arteries: correlation of intravascular US with angiographic and histopathologic findings. Radiology 206:65-74. https://doi. org/10.1148/radiology.206.1.9423653

45. Vicenzini E, Ricciardi MC, Puccinelli F et al (2007) Common carotid artery intima-media thickness determinants in a population study. J Ultrasound Med 26:427-432. https://doi.org/10.7863/jum.2007.26.4.427

46. Austin D, King RE (2016) The biological profile of unidentified human remains in a forensic context. Acad Forensic Pathol 6:370-390. https://doi.org/10.23907/2016.039

47. Garvin HM, Passalacqua NV, Uhl NM et al (2012) Developments in forensic antropology: age-at-death estimation. In: Dirkmaat DC (ed) A companion to forensic anthropology. Wiley, pp 202-223
48. Nawrocki SP (2010) The nature and sources of error in the estimation of age at death from the human skeleton. In: Letham KE, Finnegan M (eds) Age estimation of the human skeleton. Charles C Thomas, Springfield, pp 79-101

49. Lemne C, Jogestrand T, De Faire U (1995) Carotid intima-media thickness and plaque in borderline hypertension. Stroke 26:34-39. https://doi.org/10.1161/01.STR.26.1.34

50. Pignoli P, Tremoli E, Poli A et al (1986) Intimal plus medial thickness of the arterial wall: a direct measurement with ultrasound Intimal plus medial thickness of the arterial wall: a direct measurement with ultrasound imaging. Circulation 74:1399-1406. https://doi.org/10.1161/01.CIR.74.6.1399

51. Scientific Working Group for Forensic Anthropology (SWGANTH) (2013) Age estimation. 1-4. https://www.mathe wsopenaccess.com/scholarly-articles/age-assessment-in-foren sic-cases-anthropological-odontological-and-biochemical-metho ds-for-age-estimation-in-the-dead.pdf

Publisher's Note Springer Nature remains neutral with regard to jurisdictional claims in published maps and institutional affiliations. 